\title{
Impact Assessment and Project Appraisal in Cases of Coastal Erosion
}

\author{
Persson, M. \\ Halmstad University, Box 823, SE-30118 Halmstad, Sweden \\ (email: mats.persson@hh.se)
}

\begin{abstract}
There are several urban areas close to the sea and other water bodies that may be adversely affected by erosion and flooding. Global climate change, including sea-level rise and more intense and damaging storms, will increase the threats of natural hazards in several areas. Mitigating and adapting to these risks in urban areas are huge challenges for society. There is a need for a proper decision basis to build a society that is economically, socially, and environmentally sustainable. By incorporating coastal hazard and risk mapping into spatial planning, new developments can be diverted away from threatened areas. Further, by taking adaptation measures, risks in existing urban areas can be reduced. A guideline has been developed as a tool for the integration of costs and benefits in decision-making on investments in coastal zones. The guideline gives an overview of why, when, and how impact assessments and project appraisals can be made using socio-economic valuations of coastal areas affected by erosion. The guideline can be used to prioritise areas that need attention due to threatened shorelines, and to decide which preventive measures are the most efficient from a socio-economic point of view. Two case studies have been performed to demonstrate the practical application of the guideline and economic analysis and valuation in coastal management. This paper presents the results of the two case studies and discusses the prerequisites for impact assessment and project appraisal and how this is used and accepted by the users and decision-makers.
\end{abstract}

Keywords: coastal erosion, shoreline management, project appraisal, impact assessment, decision basis. 


\section{Introduction}

\subsection{The value of coastal zones and causes of coastal erosion}

Coastal areas have a variety of important economic, ecological, and social functions. People have always wanted to live close to water, in the past mostly for the convenient transportation possibilities, but today also for recreation. Over the past 50 years, the population of the European coastal municipalities has more than doubled to encompass today some 70 million people $(16 \%$ of the population of the EU). Coastal habitats are valuable for the biodiversity of their fauna and flora. Dunes and wetlands provide flood control, drinking water, and waste assimilation, and beaches are valuable assets for tourism and recreation. The estimated total value of the economic assets these coastal areas represent is as high as $€ 500$ to $€ 1000$ billion (European Commission 2004). A study carried out by the firm Firn Crichton Roberts and the University of Strathclyde (2000) assessed the socio-economic benefits generated by the adoption of the Integrated Coastal Zone Management (ICZM) approach by 21 demonstration projects in different parts of Europe. The total annual value of the benefits these zones provide exceeds $€ 18$ billion, making coastal zones within the European Union particularly valuable.

Human activities in the coastal area affect the natural coastal processes, which are also sometimes subject to severe damage by erosion and flooding. These hazards are even greater when global climate change and the anticipated sea-level rise are considered. Assessment of activities for prevention of coastal hazards should be used to maximise the benefits of measures or investments in the coastal zone. Attention should be given to the integration of coastal erosion into the decision-making process, particularly into the strategy for sustainable coastal management. It is also important that different human activities be socially and economically evaluated.

A coastline is a complex series of interlinked physical systems in which both offshore and onshore processes are involved. One of these physical processes is coastal erosion, the wearing away and redistributing of solid elements of the shoreline as well as sediment, normally by such natural forces as waves, tidal and littoral currents, and deflation. The sediments there, together with those from inland erosion transported seawards by rivers, are redistributed along the coast, providing material for dunes, beaches, marshes, and reefs (European Commission 2002).

Through the loss of land - estimated in Europe to be $15 \mathrm{~km}^{2}$ per year (EUrosion 2004a) - erosion affects important functions of the coastal zone either directly or indirectly. It can also increase the risk of flooding, inundation, and the intrusion of salt water, which, in turn, can restrict the normal use of land.

Component 3 of the Messina project established guidelines (Persson et al. 2006) for incorporating cost and benefit considerations into decision-making regarding investment initiatives in connection with coastal zones. These guidelines are part of the Coastal Management Toolkit, which represents the final result of the Messina project. Tools for taking account of costs and benefits are necessary for the 
establishment of priorities (1) between different areas in need of help because of the shoreline being threatened and (2) between different actions that could be taken that vary in their efficiency and effectiveness. Erosion management and flood protection should be long-term and endeavour to take account of all possible factors and the impact different projects can have, both socio-economically and environmentally.

A state-of-the-art report (Persson et al. 2005a) was also issued with the aim of providing insight into evaluation methods that are applicable, based in part on insights from the social sciences, providing support for the recommendations of the EUrosion study (EUrosion 2004a) that costs and risks linked to planning and investment decisions concerning coastal erosion be internalized, and that those responding to coastal erosion be accountable

For public authorities, accountability for investments has to do with the transparency of decisionmaking and its being based on clear criteria. The present study considers evaluation methods that can increase the accountability of public decision-making by making explicit the costs and effects of measures that are taken. Economic methods of this sort are aimed at supporting sound decisionmaking.

The EU directives of relevance (EIA 97/11/EC and SEA 01/42/EC), as well as the EU Commission papers that apply (EUrosion 2004b, European Commission 2004b) provide guidance on how to address the potential ecological impact of public and private projects concerned with coastal erosion. Although Strategic Environmental Assessment (SEA) and Environmental Impact Assessment (EIA) are similar in terms of the procedures and steps they involve, the latter directive is narrower in scope and in time horizon (Kornov et al. 2005). Coastal erosion often results from the cumulative, long-term effects of many different projects, both private and industrial, and SEA may be the more appropriate tool for planning aimed at reducing the impact of erosion. A recent consultation report provides guidance on how coastal erosion matters can be incorporated into SEA procedures (European Commission 2004b). It proposes ways of promoting the involvement of ICZM and of stakeholder engagement.

\subsection{Problems of concern and research aims and methods}

Since the project studied here takes as its point of departure the assumption that knowledge in the area of coastal erosion management tends to be fragmented rather than well integrated, it is of interest to consider how such knowledge is managed generally, the aim being to provide a better understanding of this fragmentation and how it can be overcome (EUrosion 2004c).

The question of coastal erosion is also increasingly coming into discussions since an acceleration of these problems is predicted as a result of global warming and subsequent sea-level rise.

This paper reports on some of the findings from the Messina project and case studies carried out (Persson \& Eriksson 2005b, Uytewaal \& van Essen 2005). It also includes a further analysis of assessment methods and project appraisal. 


\section{Analysis of coastal erosion projects}

Two major types of project appraisal can be distinguished: ex ante and ex post (see Figure 1). Ex ante appraisal is conducted prior to decision-making and aims primarily at selecting the best alternative, whereas ex post appraisal is conducted after a project has been completed and aims for the most part at lessons that can be learned from what has been done. An in medias res appraisal, evaluation of a project while it is in progress, can also be made; this is also referred to as a mid-term review. The appraisal methods that can be employed are basically the same for all three types.

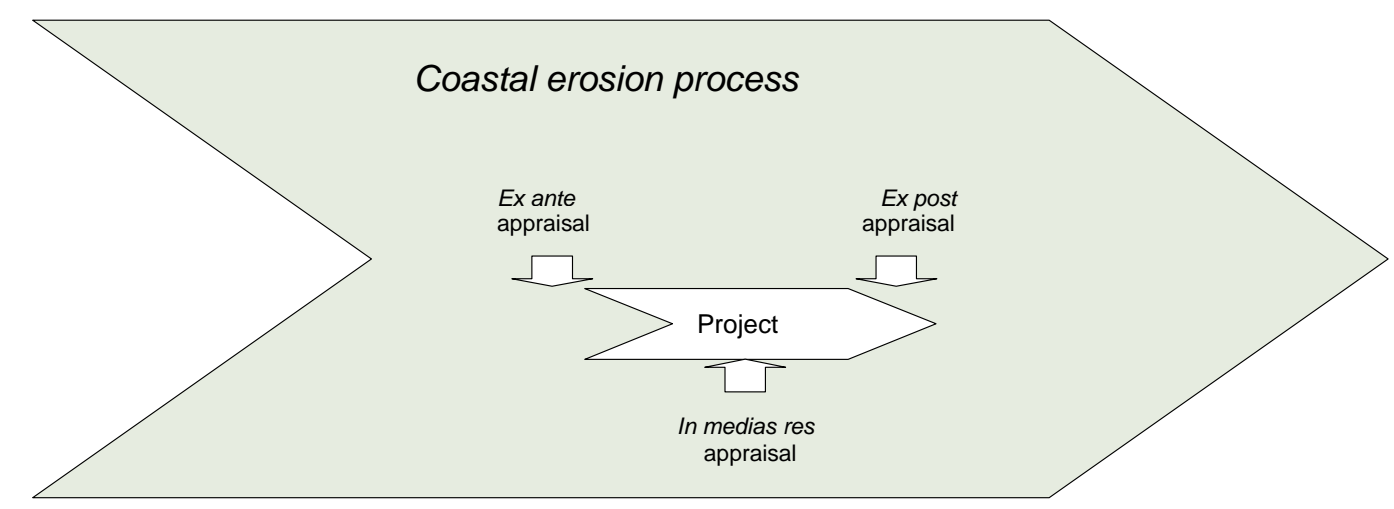

Figure 1. Different types of project appraisal

Project appraisal methods can be employed at different levels and for different purposes. Projects may be appraised for selection among different projects at different locations or for determining the best approach for dealing with erosion problems at a specific location.

Since coastal projects are long-term commitments it is essential that a long-term economic monitoring of costs and benefits be a part of them. This can help provide insights into how both current and future problems can best be dealt with.

There were big differences in awareness of the concepts of project appraisal at different levels and for different countries. Countries (such as Holland and the United Kingdom) where governmental financing is used a lot have implemented such concepts in their decision-making processes. Other countries (such as Poland and Sweden) indicated a more political process where the interest of local authorities who allocated funds from yearly budgets was more predominant. Actions to alleviate erosion problems seem to be, in some places, a never-ending story where the municipality allocates new funds for different actions almost every year. Long-term usefulness is not appraised, and eventual project appraisals are used more as tools to demonstrate that the politically taken decisions were correct. 


\subsection{Different levels of response in efforts to combat coastal erosion}

Three levels of response in efforts to combat coastal erosion and its negative impacts on society can be distinguished in the appraisal of projects in this area:

- The planning or policy level, which includes such policy options as "Hold the line", "Move seaward", "Managed realignment", and "No active intervention", and involves an understanding of natural coastal processes and awareness of the strategic sediment reservoirs that exist (EUrosion 2004a).

- The engineering or implementation level, which includes a variety of hard and soft mitigation measures. Hard techniques include breakwaters, gabions, geo-textiles, groin fields, revetments, and sea walls. Soft techniques include beach nourishment and reprofiling, and dune and marsh regeneration, together with vegetation planting and beach and cliff drainage.

- The financial level, which includes measures and incentives for controlling excess coastal urbanisation and tourism (development and land-use taxes, as well as user charges), promoting restoration and cultivation (e.g. through subsidies), arranging for the resettlement of the at-risk coastal population (financial compensation), and internalizing the costs of risk and of untoward events (insurance fees, property rights).

Economic analysis can be employed to evaluate alternative responses on a policy or project level. In any project appraisal involving economic analysis, the effects of the project, its advantages and disadvantages, and its costs and benefits need to be identified, measured, and evaluated. Human activities and interventions combine with the natural variability of coastal zone processes to produce an array of direct and indirect effects, only some of which can be valued directly in monetary terms (CEPRA 2005, Heinz Centre 2000).

\subsection{The major steps in project appraisal}

A model has been established in the Messina project to describe the normal sequence of steps in a socio-economic analysis for a project appraisal of coastal erosion projects. The model was developed based on review of case studies and the sequence of project appraisal used there. In this work attention was also aimed at establishing a model to assist the decision-making processes of public entities (Norad 1999, Inforegio 2008). The model and the normal sequence of steps in a socioeconomic analysis for a project appraisal is shown in Figure 2.

Initially, someone (e.g. a municipality, regional or national authority, or landowner) identifies that there is a risk that coastal erosion and flooding will damage values that might be worth saving. This forms the basis for performing a problem analysis leading to the definition of a project to address the hazards of erosion and flooding. The involvement of stakeholders is essential to achieve the necessary participation in the decision-making process. The proper communication and involvement in the entire project appraisal are key components in securing the acceptance of the results of a project 
appraisal. When the scope of the project is established and resources are allocated to conduct the investigation, different alternative options to cope with the hazards are analysed based on possible strategic alternatives. The effects of the different options are identified, quantified, qualified and compared using a selected evaluation method. Identification and quantification of effects is also the main task of the parallel processes of Environmental Impact Analysis (EIA) with which close cooperation is essential. By evaluating the alternative options in a "table of effects" the preferred alternative can be selected. This assists in giving transparency to the decision when public funding is used and it shows which economic, societal, and ecological factors are included in the analysis. The steps of a project appraisal are further elaborated in the following text.

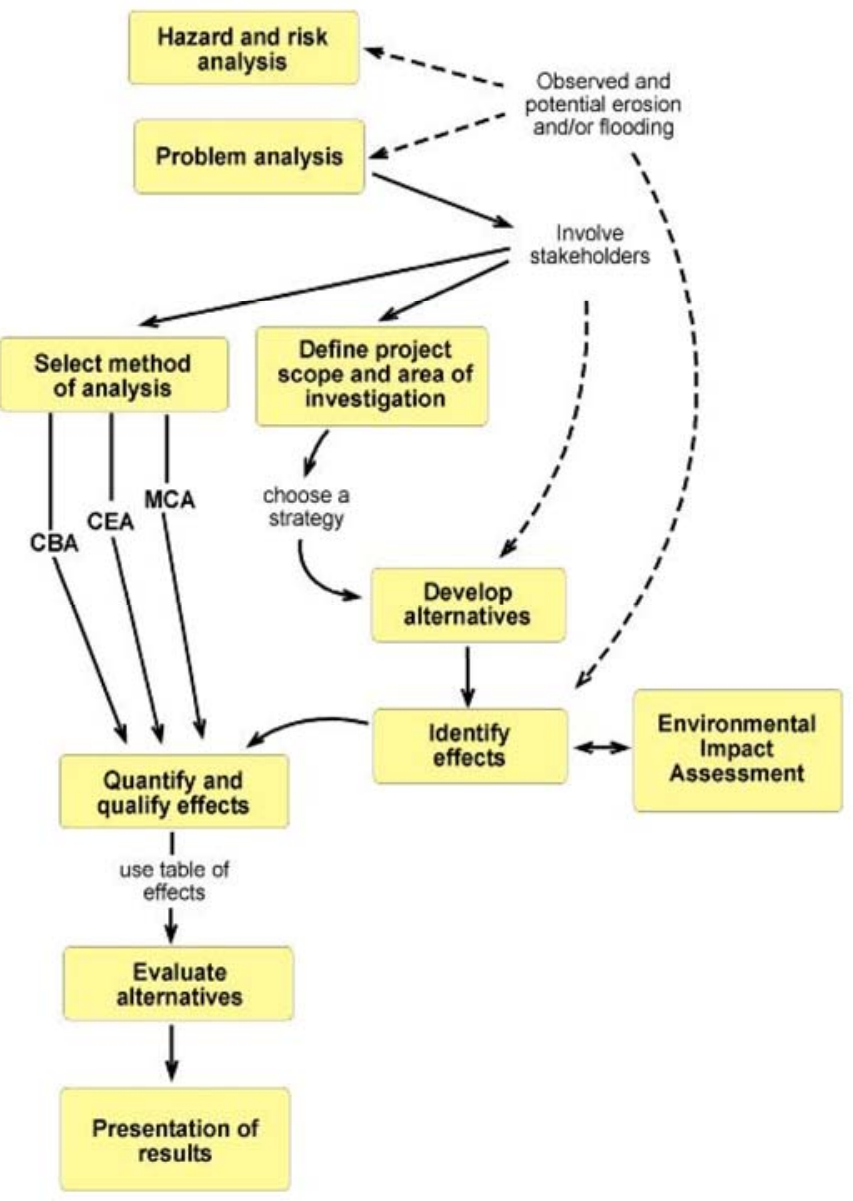

Figure 2. Steps in project appraisal in connection with erosion projects. (Adapted from Persson et al. 2006)

The definition of the steps in the model has helped in explaining and clarifying differences and similarities in the work with project appraisals. 


\subsubsection{Initiating - problem analysis}

An initial step in appraising coastal projects consists of a thorough analysis of problems of erosion at the location in question. The analysis involves the modelling of natural coastal processes and of human factors that act on the entire sediment cell. Use of hazard and risk analysis can be a useful approach for mapping and quantifying erosion (Hall et al. 2000). Questions such as "What are the causes of erosion?" and "What problems should be dealt with in the project?" should be addressed. Problem analysis of this sort is the basis for satisfactory planning and structuring of the project.

When project appraisal is started, the initiating organization needs to see to it that adequate resources for the appraisal are made available and that work is organized with a reasonable conception of the practical gains that can be expected. It is important to clarify the kinds of decisions that can be made on the basis of the appraisal and to select an appropriate evaluation method. An adequate stakeholder analysis considers all groups in society that are affected by the problem: industry, interest groups (such as environmental lobbies), other societal organisations, and the public.

The normal practice in the studied countries involved different degrees of emphasis on the initiation of project appraisals. Examples from France/Spain and Holland showed great awareness of the importance of stakeholder involvement and attention to these questions. Other countries had a more technical/engineering starting point with the technical solutions at hand.

\subsubsection{Project scope and development of alternative approaches}

After the problems to be dealt with have been analysed, the goals of the intervention to be carried out can be agreed upon. This must of course be in line with the policies and plans made at a higher level. Knowledge of the coastal erosion processes at work, of the current situation, and of prognoses that have been made of future developments are critical inputs here.

An account of alternative measures or approaches that could be taken to deal with the problems found to be present is often an integral part of project definition. One such approach is often called the "do nothing" alternative, which involves simply accepting future erosion and the problems associated with it without intervening to prevent it. Erosion contours for 10, 20, 30, etc., up to 100 years may be estimated so as to provide an indication of when different land areas will be at risk.

The various alternatives a project might consider can be classified in terms of the five generic policy options, specified by the EUrosion project (EUrosion 2004b).

- Do nothing - There is no investment in coastal defence assets or operations, i.e. no shoreline management activity.

- Managed realignment - Identifying a new line of defence and, where appropriate, constructing new defences landward of the original defences. This includes limited intervention, which means working with natural processes to reduce risks while allowing natural coastal change. 
- Hold the line - Hold the existing defence line by maintaining or changing the standard of protection.

- Move seaward - Advance the existing defence line by constructing new defences seaward of the original defences.

If "do nothing" is not considered an option (because the potential damage is considered too great, for example) it may appear more suitable to determine the net effects of the various project alternatives on the basis of a minimal intervention scheme, such as maintenance of the existing defence structures. The "do nothing" option is important in performing socio-economic analysis to ensure that public spending is used in the best way to verify that public spending is used in the best way. The work needed to predict future erosion and coastline developments is largely dependent on historical data, and there seems to be a general shortage of data in this regard. Holland demonstrated good systems of monitoring the shoreline development.

\subsubsection{Identification of effects}

The effects of all project alternatives, including the "do nothing" one, need to be identified, quantified, and considered in terms of quality. Effects may be either desirable or undesirable, and either intended or unintended (Adamus et al. 1987, Barbier et al. 1997, Kornov et al. 2005, Ruijgrok 1999, Storey \& Noble 2005, Turner 2000, Turner et al. 2001).

A good way of presenting the effects is in a "table of effects", in which the effects are sorted into categories, such as effects on the local economy and effects on nature. They can also be ordered in a preliminary way in terms of significance so as to indicate to the analysing team the major effects with which the evaluation can start.

In the process of effect identification, three different types of effects can be distinguished:

- Direct effects stem directly from a project and have a direct influence on its initiators or users. Examples are the safeguarding of property and land, and placing a limit on the construction costs of a project.

- Indirect effects arise from events that are only triggered by the project and that affect directly not the initiator or the users but other groups in society. Examples are improvement of the infrastructure or improvement of some particular amenity in a way that upgrades the attractiveness of the region or area in question.

- External effects, finally, are direct or indirect effects that cannot be measured by market prices. Many sorts of environmental impacts fall into this category.

Table 1 is an example of a table of effects. To account for the special condition of this case study, the Effects on current use relates to existing properties/land that will be affected in the different project 
alternatives. Effects on future use relates to new land areas that will be created in the different project alternatives.

Table 1. Table of effects - Flooding study, Maas (adapted from Brouwer et al. 2003 p. 96)

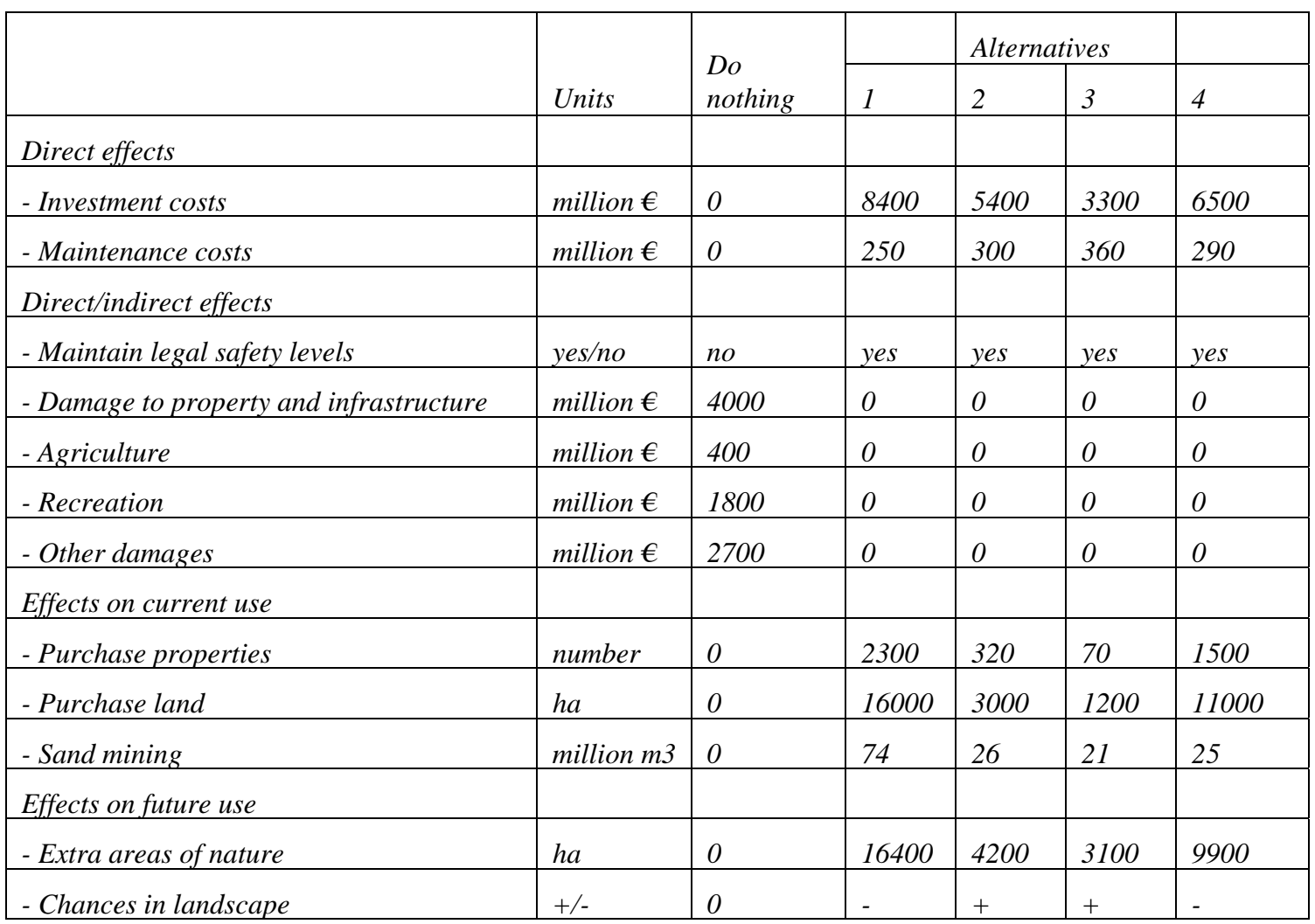

The different examples studied indicate the use of different methods and taxonomies to organise effects. This, to some extent, hinders comparison and sharing of data between projects and countries.

\subsubsection{Quantifying and qualifying effects}

\section{Quantifying effects}

After having identified the relevant effects, these should be described and quantified to the extent possible for each of the alternatives, including the "do nothing" alternative. For example, if coastal erosion endangers an inhabited area, account should be taken of the number of hectares, the number of houses, their average market value, and the number of persons involved. Since this is one of the basic steps in project appraisal, it is highly relevant that the information and research on the effects be of good quality, and that as much of it as possible be quantified. Cooperation between persons of different backgrounds and expertise can be important in determining what effects should be analysed, and what measures should be used to express the effects (hectares of biotope lost, numbers of species lost, number of houses damaged, number of tourists affected, etc.). The identification and quantification of effects is the main task of EIA/SEA and of hazard analysis. 


\section{Qualifying effects}

"Qualifying the effects" means assigning a qualitative value to each of the identified effects. The values can be monetary or non-monetary. Monetary values can be represented by investment costs, production losses, and costs of restoring damage. Non-monetary values include classification and ordinal or interval scales that describe the effects of different alternatives (Kahn 1998, Ledoux \& Turner 2002, Oden et al. 2003). The main reason for using monetary qualification is that it is easy to relate to in budgetary terms, etc., and it is easy to make summaries. The problem with monetary qualification lies in the actual appropriateness of making trade-offs between different costs and benefits and the transfer of wealth that can occur (Boardman et al. 2001).

The most obvious method of valuating monetary effects is to use market prices. In a perfectly competitive market, this is the simplest possibility and the recommended way to begin using investment costs, for example, taking the value of lost property, or operational and maintenance costs, as a percentage of total investments.

An alternative to pricing is to work with non-monetary values using an interval or ordinal scale, or using an ordinal scale for different aspects of the potential problems associated with the alternatives being assessed. A non-monetary valuation deals with the same causes and effects but can group them differently. Non-monetary values also have to take account of future changes. The valuation criteria and the reasons involved may also change over time, a matter that needs to be included in the project appraisal in some way.

The examples studied show that conducting a total project appraisal in which account is taken of all factors that affect the project in question can require enormous resources. One can recommend that the effects first be valuated in a preliminary way and be ordered in terms of importance. This should be done together with the project initiator, experts, and key stakeholders so as to ensure a relevant outcome.

\subsubsection{Comparing alternatives - selection of an evaluation method}

Several methods for assessment and evaluation are available. The methods most commonly used are Cost-Benefit Analysis (CBA), Cost-Effectiveness Analysis (CEA), and Multi-Criteria Analysis (MCA). CBA and CEA are economic evaluation methods, whereas MCA allows non-monetary input (Boardman et al. 2001, Herwijnen 1999, Herwijnen \& Janssen 2004, Janssen 2001, Levin \& McEwan 2000). The DG Regional Policy has issued a guide to Cost-Benefit Analysis of investment projects (Inforegio 2008); however, this guide does not address erosion problems or integrated coastal zone management.

In a social CBA the decision criterion is such that the lowest ratio of costs to benefits that is found is selected. If the benefits of a project exceed its costs (making it clearly worthwhile) the project is considered worth doing from a societal point of view. For a CEA, the lowest-cost alternative is calculated (i.e. such as the costs per $\mathrm{m}$ of shoreline that is protected). In an MCA, each effect is assigned a score, and effects differ in the importance (weights) assigned them; the option with the best total score is selected. CBA and MCA include the valuation of investment costs and of economic, 
ecological, and socio-cultural effects, whereas CEA does not include a valuation of all types of effects (Bonte et al. 1997, Janssen \& Munda 1999).

The main way in which an MCA differs from the others is that it can make use of larger amounts of subjective qualitative data since it uses valuation in the form of interval scores and assigns weights to effects and factors. CBA and CEA, in contrast, valuate in monetary terms. For an interval score, an alternative is given a score, such as between 1 and 10, for a given effect. Valuation then means assigning a discrete monetary value to the effect. If an alternative can be valuated monetarily, use of an interval scale results in a loss of information and accuracy.

The studied countries demonstrated different preferences and use of methods. Most distinct in this respect was the directive of the Defra in the UK that has developed a model of CBA to be used when prioritising between projects. Holland uses similar approaches. In Sweden and Poland there were no governmental guidelines. In cases where guidelines are weak, it is up to the initiator of a project to arrange funds for the project using facts, figures, project appraisal, impact assessment, arguments, public opinions, etc., based on the opportunities available at any given time with local, governmental, EU, or research funds.

\section{Conclusions}

\subsection{General observations}

To a large extent it is the public that carries the costs of erosion, a matter that may not be sustainable in the long run. If authorities, decision-makers generally, and initiators of technical change are fully aware of the risks of both erosion and flooding it will be easier to achieve and create the appropriate priorities, procedures, and distribution of funding in this area and to adequately internalize erosion and flooding costs. Since the predicted future changes in climate and rise in sea level will surely increase the risk in Europe of erosion and flooding, appropriate measures for protection and defence against such processes need to be decided on now.

It is obvious that in Europe as a whole several different approaches to coastal management in general and to erosion in particular are employed, economic assessment playing only a minor role. The Defra approach (including the point system) and the OEEI guidelines (2000) could be good starting points for introducing and developing more systematic and rigorous procedures for supporting the decision process here.

Balanced choices and decisions that are readily accepted can best be taken if the impact of every economic, ecological, and social project is taken into account. An integrated assessment of the various impacts, together with stakeholder participation, should lead to more sustainable and satisfactory solutions. The choice to be made of the extent to which assessments are integrated in this way depends upon the information needs involved, the complexity of the decision, and the resources available. 
A more comprehensive and harmonised approach of the EU as a whole to Integrated Coastal Zone Management (ICZM) is needed. Use of a centralized data collection system in connection with this would be a step in this direction. Such a system should also reflect an understanding of the natural processes involved locally. In addition, a more adequate policy and strategy toward coastal zone management projects would be useful. These should encompass generic policy options both of holding the line and of realignment, as well as a combination of soft and hard engineering approaches. There is a need for greater cooperation between the different countries in the EU and between the different projects in efforts to achieve a more efficient and better coordinated exchange of data and experience in such matters. Cooperation is also needed in the introduction of procedures and instruments supporting the making of sustainable decisions on measures to combat erosion in coastal areas. These issues have also been addressed by the EU demonstration programme on ICZM integrated coastal zone management (Rupprecht 2006).

The assessment methods discussed in this paper, Cost-Benefit Analysis, Cost-Effectiveness Analysis and Multi-Criteria Analysis, represent the major tools for evaluating the adequacy of use of public funds for coastal erosion projects.

\subsection{The use of CBA}

An economic analysis is necessary as a basis for decision-making in coastal management. With a CBA, a long-term perspective is generated and the influence over time of natural change and humanmade intervention will be demonstrated. In a case like that in Ystad Sandskog, where land is lost to the sea, it is of direct interest for the landowner to evaluate future possibilities. The adjacent coastal areas are reasonably stable and do not influence the part of the beach that has been studied.

A CBA adopted on regional or national levels may help with prioritising different planned projects, and the different alternatives can be analysed using the same methods to estimate quantities and to establish cost data. In the case of single-project analysis, over- or underestimating may be more systematic and may not pose a big problem as long as the options are treated equally. Technical evaluation and models for evaluating shoreline development and the impact of human-made activities on erosion and the shoreline are fundamental for a reliable analysis.

\subsection{Final remarks}

Socio-economic analyses are necessary when decisions have to be made in coastal management. Such an analysis could be performed either in an early land use planning phase or when protection measures must be taken. That would offer possibilities to maximise the benefits of future measures or investments in the coastal zone.

In the Messina guideline for socio-economic analyses of shorelines practical recommendations are given to be used by county administrations, municipalities, governmental authorities, private landowners, etc., dealing with or affected by coastal erosion issues. 


\section{References}

Adamus P R et al. (1987) Wetland evaluation techniques, WRP-DE-2 Washington, DC.

Barbier E, Acreman M, Knowler D (1997) Economic valuation of wetlands, Ramsar Convention Bureau, Gland, Switzerland.

Boardman A, Greenberg D, Vining A, Weimer D (2001) Cost-Benefit Analysis - Concepts and Practice, Second edition, Prentice Hall.

Bonte R J et al. (1997) Notitie over multi-criteria analyse in milieu-effectrapportage, Commissie voor milieu-effectrapportage, Utrecht.

Brouwer R, de Boer J, van Ek R, Hisschemöller M (2003) Baten van Water in Geld, Groen, Gevoel, RIZA rapport 2003.026. ISBN 9036956358. Lelystad.

CEPRA - Coastal Erosion Planning \& Response Act - Report to the 79th Texas Legislature April 2005. Texas General Land Office. http://www.glo.state.tx.us/coastal/erosion/cepra.html.

Defra (2000 - 2004) Project appraisal guidance (FCDPAG 1-6): procedural guidance for operating authorities economic, environmental appraisal, planning, approaches to risk and supplementary notes; Making space for water: Developing a new Government strategy for flood and coastal erosion risk management (2004) (available online http://www.defra.gov.uk/environ/fcd/pubs/pagn/default.htm [accessed on 11-10-2009]).

European Commission (2002) Trends of coastal erosion in Europe, EUCC, Leiden.

European Commission (2004) Living with Coastal Erosion in Europe, results from the EUrosion study.

European Commission (2004a) EU Commission puts spotlight on coastal erosion, press release, May 2004.

European Commission (2004b) Development of a guidance document on Strategic Environmental Assessment (SEA) and coastal erosion.

EUrosion (2004a) Living with Coastal Erosion in Europe: Sediment and Space for Sustainability: Guidelines for incorporating coastal erosion issues into Environmental Assessment (EA) procedures, prepared for European Commission Directorate General Environment, Service contract B43301/2001/329175/MAR/B3 (available online http://www.EUrosion.org/reports-online/part5_4.pdf [assessed on 11-10-2009]).

EUrosion (2004b) A guide to coastal management practices in Europe (available online http://www.eurosion.org/reports-online/reports.html [assessed on 11-10-2009]). 
EUrosion (2004c) Living with Coastal Erosion in Europe: Sediment and Space for Sustainability: Guidelines for incorporating coastal erosion issues into Environmental Assessment (EA) procedures, prepared for European Commission Directorate General Environment, Service contract B43301/2001/329175/MAR/B3 (available online http://www.EUrosion.org/reports-online/part4.pdf [assessed on 11-10-2009]).

Firn Crichton Roberts Ltd, and University of Strathclyde (2000) An assessment of the socio-economic costs \& benefits of integrated coastal zone management.

Gamboa, G., Komen, A. Roca, E. (2004) Social Multicriteria Evaluation of Alternative Solutions for Coastal Erosion: The Case of Séte's Lido. Universitat Autònoma de Barcelona (available online http://www.interreg-messina.org/publications.htm [accessed on 2/3/2010]).

Hall J W et al. (2000) Risk based assessment of coastal cliff protection, Proceedings of the Institution of Civil Engineers - Water and Maritime Engineering, 142, p.127-139.

Heinz Centre (2000) Evaluation of erosion hazards (available online http://www.fema.gov/pdf/library/erosion.pdf [accessed on 12/01/2006]).

Herwijnen M v, Janssen R (2005) Software support for multi-criteria decision making. Sustainable Management of Water Resources: an integrated approach. In Giupponi C, Jakeman T \& Kasserberg D (Eds.), Cheltenham: Edward Elgar.

Herwijnen M v (1999) Spatial decision support for environmental management, PhD thesis, Vrije Universiteit, Amsterdam.

Inforegio (2008) Guide to cost-benefit analysis of investment projects. Published by DG Regional Policy (available online http://ec.europa.eu/regional_policy/sources/docgener/guides/ cost/guide2008_en.pdf [accessed on 2/03/2010]).

IVM (2001) Baten van water, rapportnummer O-01/07, Vrije Universiteit, Amsterdam and Resource Analysis, Delft.

Janssen R, Munda G (1999) Multi-criteria methods in Bergh, J.C.J.M. (ed) Handbook of environmental and resource economics, Edgar Elgar, Cheltenham.

Janssen R (2001) On the use of multi-criteria decision analysis in Environmental Impact Assessment, Journal of multi-criteria analysis, 10. pp.101-109.

Kahn J R (1998) The economic approach to environmental and natural resources, Thomson, South Western, Ohio USA. 
Kornov L, Christensen P, Nielsen E H (2005) Mission impossible: does environmental impact assessment in Denmark secure a holistic approach to the environment? In Impact Assessment and Project Appraisal, Volume 23 No 4 pp. 303-314.

Ledoux L, Turner R K (2002) Valuing ocean and coastal resources, Ocean \& Coastal Management, 45, pp. 583-616.

Levin H M, McEwan P J (2000) Cost-Effectiveness Analysis - Methods and Applications, Second Edition, Sage publications.

Norad (1999) The Logical Framework Approach (LFA) Handbook for objectives-oriented planning, Fourth edition, Norwegian Agency for Development Cooperation.

Nunes P A D L, van den Bergh J C J M, Nijkamp P (2000) Ecological-Economic Analysis and Valuation of Biodiversity, Tinbergen Institute Discussion Paper 2000-100/3.

Oden M, Butler K, Paterson R (2003) Preserving Texas coastal assets: Economic and natural resource evaluation of erosion control projects, Technical report to the Texas General Land Office, University of Texas, Austin.

OEEI (2000) Evaluatie van grote infrastructuurprojecten. Leidraad voor kosten-baten analyse, cpb, NEI, Den Haag.

Persson M, Rankka K, Rydell B, Uytewaal E (2006) Valuing the shoreline - Guideline for socioeconomic analyses (available online http://www.interreg-messina.org/publications.htm [accessed on 2/3/2010]).

Persson M, Uytewaal E, Rankka K, Rydell B (2005a) Socio-economic methods for evaluating decision in coastal erosion management - State-of-the-art (available online http://www.interregmessina.org/publications.htm [accessed on 2/3/2010]).

Persson M, Eriksson A-S (2005b) Socio-Economic study - Ystad Sandskog. (available online http://www.interreg-messina.org/publications.htm [accessed on 2/3/2010]).

Ruijgrok E C M (1999) Valuation of nature in coastal zones, Dissertation, Vrije Universiteit, Amsterdam.

Rupprecht Consult (2006) Evaluation of Integrated Coastal Zone Management (ICZM) in Europe Final report. (available online http://ec.europa.eu/environment/iczm/pdf/ evaluation_iczm_report.pdf [accessed on 18/05/2007]).

Storey K, Noble B (2005) Socio-economic effects monitoring: toward improvements informed by biophysical effects monitoring. In Impact Assessment and Project Appraisal, Volume 23 No 3 page 210-214. 
Turner R K, Bateman I J, Adger N editors (2001) Economics of coastal and water resources, Kluwer Academic Publishers, Dordrecht.

Turner R K (2000) Integrating natural and socio-economic science in coastal management, Journal of Marine Systems 25, pp. 447-460.

Uytewaal E, van Essen K (2005) Socio-Economic Study: Coastal Extension South Holland. (available online http://www.interreg-messina.org/publications.htm [accessed on 2/3/2010]). 